\title{
Impact of E-commerce on Business Performance
}

\author{
Aleksandar Andonov, Georgi P. Dimitrov, Vasil Totev
}

\author{
ULSIT, 119, Tzarigradsko shose blvd, Sofia, Bulgaria
}

\begin{abstract}
E-commerce has emerged to be one of the most successful business models that have provided numerous benefits to businesses in the contemporary environment. This study focuses on assessing the impact of E-commerce on business performance. Some imperative impacts have been the international marketplace, no time constraints, better relationship building with customers, lesser fixed costs, and some more.
\end{abstract}

Keywords - E-commerce, business performance, business impact.

\section{Introduction}

In order to affect high quality of the papers, the authors are requested to follow instructions given in this sample paper. Regular length of the papers is 5 to 12 pages. The business environment has been becoming complex with time, and it has become imperative for businesses to keep evolving and adapting to new changes taking place. Various business models and approaches have been developed over the past and E-commerce among them has emerged to be a critical and significant aspect. E-commerce is a business model that allows organisations and individuals to sell and buy things over the internet.

DOI: 10.18421/TEM104-09

https://doi.org/10.18421/TEM104-09

Corresponding author: Georgi P.Dimitrov, ULSIT, 119, Tzarigradsko shose blvd, Sofia, Bulgaria.

Email: g.dimitrov@unibit.bg

Received: 20 August 2021.

Revised: 22 September 2021.

Accepted: 28 September 2021.

Published: 26 November 2021.

(cc) BY-NC-ND (C) 2021 Aleksandar Andonov, Georgi P. Dimitrov \& Vasil Totev; published by UIKTEN. This work is licensed under the Creative Commons AttributionNonCommercial-NoDerivs 4.0 License.

The article is published with Open Access at www.temjournal.com
Developing a presence online has become extremely critical in the modern world and businesses have been inclined towards inculcating the use of the internet in their business operations and activities

With the presence of E-commerce, businesses have been given the opportunity not only to market their products and services online but also to offer the products for purchase to a huge set of consumers. With regards to E-commerce, there are three major types of it that are implemented in the contemporary environment and they are businesses-to-business, consumer-to-business, business-to-consumer. The presence and development of E-commerce have provided numerous opportunities to organisations and it has had varied impacts as well [1].

This study is focused on identifying and assessing how E-commerce impacts the performance of organisations. The research is inclined to explore the opportunities provided to businesses through Ecommerce and how they may optimise on such opportunities to augment their overall performance. The purpose is to further establish the significance of E-commerce and its implications in the contemporary environment along with identifying the challenges associated with it and understanding the related dynamics

\section{A. Research Question}

The main objective of the study is to assess the impact of E-commerce on business performance. In this regard, the following research question has been developed:

What is the impact of E-commerce on business performance?

\section{Background}

E-commerce today has become a highly imperative and useful business model that is used by a huge set of organisations all over the world. Michael Aldrich in the year 1979 introduced and invented online shopping to provide the opportunity of enabling online transactions between businesses and consumers or between one business and another. This 
concept and technique were later called as Ecommerce in which business took the use of the internet to conduct transactions. Online shopping was initiated in the year 1991 when the internet was opened to the public. The first company that started its E-commerce operations was the Amazon in the United States [2].

\section{Literature Review}

\section{A. Concept and Implementation of E-commerce}

E-commerce has been regarded as the activity of buying and selling products and services using the internet. The business model is designed in a way that it provides its offerings online and gives the opportunity to the consumers for selecting and purchasing the desired products. Planning for Ecommerce business is critical as this allows the firm to take into consideration the related dynamics and implementation of the business model, consider the probable adversities and challenges that may arise during the process and functionality [3]. The planning further considers the associated risks and limitations which the company may be exposed to and so an effective contingency plan may be developed through critical planning and considerations. The other aspect is technology selection along with mediums and approaches. To function online, it is vital that the firm selects the most adequate technology to carry out the desired tasks and activities. In this regard, the considerations need to be made in accordance with the nature and type of customers along with the capabilities, resources, and kind of business that is involved in the process. The technology usage may differ for varied businesses and their specific target audiences and a critical analysis in this regard could be conducted to ensure optimum results [4]. (See Figure 1)

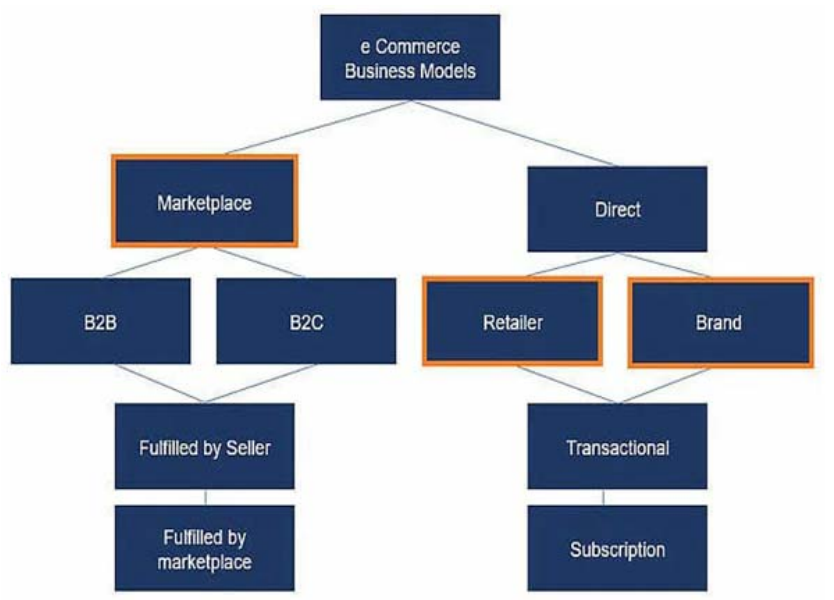

Figure 1. E-commerce Business Model Source

Customer acquisition could be regarded as another critical element related to the implementation of E- commerce. Businesses use a huge range of tools for reaching out to consumers such as search engine marketing, display advertisement, email campaigns, social media marketing, and much more. With regards to the sales principle of awareness, interest, desire, and action (AIDA) it could be noted that customer acquisition cost will be higher for the brands that are new in the market, and in comparison, it would be lower for those that have already established an offline presence in the industry. Customer engagement is another imperative dynamic related to the successful implementation of Ecommerce. The fact that customer concerns and requirements are constantly evolving, it has become vital for businesses to make sure that their developed online business model has the ability and features of providing a robust support mechanism for queries, issues, and information to the consumers. In this regard, social media presence has been identified to be a successful approach to catering to such concerns and effectively implementing online business activities.

\section{B. Organizational Performance}

Organizational performance is one of the main areas of consideration and focuses on businesses. Every organisation regardless of whatever industry it is operating in attempts to enhance its performance to sustain in the industry and grow in the long run. Different strategies and techniques are used by companies to augment the performance and while some of them turn out to be successful for one business it may not be equally beneficial for the other $[5],[6],[7]$. Organizational performance mainly focuses on three areas of the company's outcome and they are identified as product market performance, customer satisfaction, and product service quality. To measure the performance of organisations, effectiveness and efficiency are observed in terms of how well and to what extent the firm has been able to attain its objectives. Even though certain firms can attain strategic resources, poor efficiency, and effectiveness lead to negatively impact the outcomes and results. Having said this, it is vital to make sure that every activity and task of the company is carried out in the most appropriate manner [8].

The performance of the company could be identified through the product market performance.

Business performance is among the few major objectives that are taken into keen consideration by almost every business. The approaches and strategies of the business are aligned towards the attainment of improved performance and the resources are allocated for the same purpose as well. Even though all companies wish to improve their performance, the internal and external environment majorly affects the companies and impacts how well the performance will take place. 


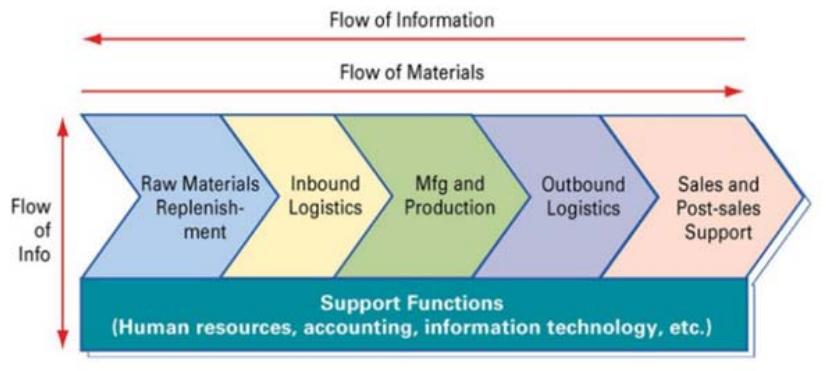

Figure 2. E-commerce and E-Business Concepts Source [8]

Some of the most imperative approaches that are adopted by firms to increase business performance are better resource allocation, effective leadership, effective culture, training and development, innovation, and much more (See Figure 2). Each of these aspects has its own pros and cons which suggests that a single method may not allow organisations to achieve their desired performancerelated objectives.

\section{E-commerce and Business Performance}

E-commerce has emerged to be one of the most imperative innovations in the contemporary environment. Businesses all around the world functioning in varied industries have inclined towards the usage of E-commerce to optimise the opportunities and enhance its overall performance. Ecommerce and business performance could be considered associated with each other in different ways.

Giving high significance to training and development has to be a part of the organizational culture in order to make sure that every employee is provided the right set of training and their skills to get more improved. While this may take up certain resources of the business initially, the results attained from this would become far more superior in the long run.

E-commerce further has led to an increase in the efficiency of production and operations management. With an online presence, it has become more feasible for firms to take up orders from the customers, get them produced and delivered in an effective way. Businesses working upon the E-commerce models have been given the opportunity to get the products delivered to customers within no time frame. The processing time has been lowered due to the integration of several departments of the company such as finance, marketing, and much more.

Using E-commerce, businesses have been given the opportunity to enter new markets and lead towards internationalisation. With the use of online platforms organisations have been given the opportunity to reach out to customers all over the world. It has been assessed by firms that to grow and expand their operations it is necessary that the demand of their products and services is found in varied countries and societies. Today, as competition has gotten fiercer and complexities have risen, firms have led to incline more towards internationalisation and global operations [9]. Many at times, when businesses are unable to find enough demand locally, they tend to enter into different markets where they can find ample demand for their offerings. This market development becomes easier and more feasible with the use of E-commerce where the presence of the company is not physically situated at any place. The target of firms in E-commerce is to identify demand for their products and services all over the world and then develop ways through which the demand could be fulfilled. Even though effective supply chain management is required for this, many firms have been able to successfully implement the strategies and ensure good performance.

Legal and law issues related to E-commerce also need to be taken into consideration as they tend to negatively affect businesses in the industry. Many rules and policies have been developed by the governments linked to E-commerce in the recent past and that has limited the efficiency and performance of businesses. Various legal and ethical issues take place when functioning online and this restricts and poses limitations on how well the firm does overall. Governments and other related legal authorities have developed certain laws related to customer privacy, transparency, copyrights, operations, marketing, and varied other areas that limit and impact the way Ebusinesses function. Firms need to make sure that they understand every law and policy that is related to them depending on the nature of business. Once this is done, all the operations and activities need to be designed in accordance to avoid any sort of complexities or issues in the future [10].

\section{Result and Discussion}

\section{A. Benefits of E-commerce on Business}

E-commerce has been identified to be having numerous benefits for businesses and it majorly depends on the efficiency of the firm on how it plans to optimise the available opportunities. The fact that E-commerce is a business model that operates without having a physical presence (in terms of customer point of contact) is given the opportunity to save most of its operational costs. E-businesses do not develop physical stores (brick and mortar) to present their offerings to customers. In most of the cases, costs associated with processing, storing, distributing, and retrieving are also lowered and this again contributes to major cost saving for companies. 
The significance of E-commerce has augmented over the years and it has been identified that in the year 2018 e-commerce represented $18 \%$ of the total sales in EU countries. Further, it has been found that one out of five firms in EU countries use E-commerce in the year 2017. Also, businesses that implemented Ecommerce have further been able to increase their sales by $7 \%$ during the years of 2008 to 2018 . Also, the need for human capital has also decreased significantly due to E-commerce and this further saves ample cost overall. E-commerce relies highly on the aspect of efficiency and effectiveness which focuses on optimisation of every function and operation. The fact that physical stores do not have to be operated in E-commerce, a huge amount of liabilities related to administration costs, operational costs, human resource costs, and much more are set aside [11].

Cost-saving has been identified to be one of the major advantages for companies in E-commerce. Most of the functions through E-commerce are carried out at lesser expenses due to the model and its implementation. The work operations have completely changed in E-commerce and organisations have been keen towards establishing a greater understanding of how the benefits could be maximised. A considerable number of businesses in E-commerce have streamlined their work activities. In many cases, businesses ship their products directly from the wholesaler, and the need to develop a store is lowered down. For physical stores, having a warehouse is important and while this has its own benefits, the costs for such businesses are much higher in terms of salaries, administration costs, operational costs, and much more. Warehouse management is a complex activity and E-commerce has allowed organisations to operate without even having a warehouse or storage place. Many times, the orders are placed directly to the wholesalers, and thirst party logistics are used to deliver the goods to the customers directly. While this reduces costs, it also allows firms to save ample time and effort involved in transportation and handling of products.

One of the other benefits of E-commerce is mass customisation. The aspect and element of customisation have emerged to be very useful and significant for companies. Through this, businesses provide an opportunity to the customers in which they can choose and customise according to their requirements. E-commerce has completely changed and revolutionised the way consumers buy products and services [12]. Every individual is given an opportunity to communicate and specify what exactly they desire and then goods are developed specially in accordance with the preferences of customers. For instance, earlier customers only had the choice to choose the colour of the car. Now, companies provide the opportunity to customers for developing cars in accordance with the requirements and customise various aspects of it while manufacturing. While such customised products may be charged slightly higher than the normal price, a considerable number of consumers incline towards customisation. As this allows customers to be more satisfied and content, businesses can enhance their sales and establish a good image in the industry.

Lower telecommunication cost is considered another major benefit for businesses in E-commerce. Businesses all around the globe previously used telephones for the purpose of sales and marketing. Now, with the prevalence of the internet, organisations have been given the opportunity to carry out most of their work activities using it. Internet is much cheaper than the value-added networks and this allows businesses to save ample costs. Another element related to this is the factor of time, as using the internet is much faster and effective in terms of reaching out to customers and sending any sort of information. The business model significantly supports innovation and using the internet for communication is one of the major advantages taken by E-businesses.

While several different benefits have been associated with E-commerce, no time constraint is one of the most evident advantages experienced by businesses. Operating on an online business model, organisations are given an opportunity to always function without having any time limitations of opening or closing the stores. Many online businesses are operational $24 / 7$ to enhance their sales and revenue streams, catering to different sorts of customers and their requirements. Even today, businesses functioning through a brick-and-mortar model have to remain operational only during working hours and this restricts such firms to optimise their sales to a certain extent. The fact that E-businesses need comparatively much lesser employees, managing a double shift to the extent the work timings remain feasible. With minimum fixed costs, e-businesses can cater to the demands of customers at any time of the day and process their orders immediately without any delays.

One of the other benefits related to E-commerce for businesses is that they are given an international marketplace to function. Traditionally firms were bound to operate within a geographical boundary and cater to only a limited number of customers that it could reach out to. Organisations through Ecommerce can approach a wide range of customers globally and meet their needs and demands. Firms using the internet become available to individuals located in different parts of the world. Customers have to use the internet to reach out to the website of the brand and look for the products they require. The 
organisation may then proceed with processing their orders and shipping them to the provided addresses. It could therefore be assessed that E-commerce allows businesses to expand their markets and customer base to various geographic areas and cater to the needs and requirements of consumers in an effective manner. While the international marketplace potentially increases the sales and revenue generation of businesses it is also imperative for the companies to make sure that operational efficiency is ensured during the process.

Along with the opportunity to expand to an international marketplace, businesses also face various responsibilities and challenges. The fact that competition in the international market is considerably high, firms in E-commerce have to focus on establishing uniqueness through which a rare identity could be attained. With limited resources and capabilities, aspects such as resource allocation and optimisation become critical to success [13]. It has further been observed in one of the studies related to E-commerce and its impact on business performance that the assessment of cost positions (labour, maintenance, and inventory cost) impact on firm's efficiency depicts a positive result i.e., the business efficiency grows by $57.8 \%$ on the whole. With regards to inventory cost and availability, it has been assessed that the adoption of E-commerce has reduced the average inventory level from 17 million to 10 million. Also, the average inventory cost in result reduced from 1.785 to 1.050 Litas, which eventually contributes in better business performance [13].

\section{B. Usage and Significance of E-commerce}

E-commerce has resulted in being a highly imperative concept for businesses in the modern world. Organisations can make use of the technology to not only reach out to a higher set of audiences but also increase the effectiveness and efficiency of work. The elimination of geographical boundaries has been the core use and significance of Ecommerce that has allowed organisations to expand their work operations and effectively carry out market development. Firms have been making use of global consumer base and identify the demand of their products and services in various markets of the world. In the emerging economy, E-commerce has resulted in being a necessary and vital element of business strategy. E-commerce has caused downward pressure on inflation due to increased competition and cost savings. With more and more businesses establishing their presence in the industry through Ecommerce, the prices of products and services have reduced. Competition has influenced companies to keep their prices at a minimum because customers have ample substitutes in the market.

E-commerce has made it easier for companies to set-up their presence and start their businesses due to lesser investment requirements and easier operations. With E-commerce, organisations have been able to start their projects and start functioning at a small scale. Due to no need of developing a physical presence, lesser initial capital and investment is required and this promotes business start-ups. With a higher number of E-commerce businesses taking place, more jobs are created in the economy and better employment rates are established. Customers on the other hand are given a good purchase experience through which they can easily go through a huge variety of products and chose their required goods and services without any hassle or wastage of time. E-commerce has changed the way businesses used to carry out their operational and functional activities, allowing organisations to optimise on various opportunities. Going global, a huge number of businesses have been able to enter new markets and make use of higher outreach overall.

Further, internet technology for businesses allows them to improve their communication and allow doing business more easily. Earlier, it was highly challenging for customers to interact or communicate with companies or present their concerns. Reaching out to businesses and forwarding the concerns to the right authorities was considered daunting for consumers and this often led to dissatisfaction between individuals. Also, the whole process of communication was very time taking and lengthy which restricted consumers from presenting their queries to the firms or give their feedback for improvements. E-commerce has made it much easier and feasible for consumers to interact with the companies and put forward their concerns regarding the products and services. Using the internet, customers can easily communicate with the concerned authorities and attain prompt responses from the brand. This has allowed businesses to achieve high customer satisfaction and retain consumers for a longer period. Considering that customer retention is difficult in the contemporary environment, effective communication results in adding value to this aspect.

\section{Challenges Related to E-commerce Implementation}

While it has been assessed that there are several benefits associated with E-commerce, businesses also face numerous challenges while implementing it in an adequate manner. One of the most evident challenges related to E-commerce could be considered as cyber-security. Companies that 
establish their presence online are exposed to the risk of cyber-security threats. Various malicious individuals and companies are involved in the process of hacking online firms for several different reasons. While some get involved in the process of hacking due to ransom demands, others hack for information and data. Cyber-attacks have become a major issue for businesses functioning online and this has led to a limit in their efficiency and effectiveness overall. In order to overcome this challenge, companies hire ethical hackers and other experts, but nothing has been able to provide the desired outcomes. While cyber-attacks could be reduced, they cannot be completely mitigated and a certain probability of it always remains. With improvements in technology, where companies have been involved in strengthening their systems and networks, malicious hackers have also been increasing their knowledge and skills to achieve their desired targets.

Website traffic and visitor conversion are other challenges associated with E-commerce and business functioning online. Organisations operating online have to make sure that the user interface is friendly and easy to use. While this aspect is critical, one of the other considerations is the effectiveness of a website. Many at times, websites tend to crash or perform poorly due to high traffic load. This leads to having a poor impact on customers and negatively affects the image and position of the brand [14]. Further, visitor conversion is also a challenge as many customers that visit the company's website do not involve in the purchase and leave the webpage after browsing. Firms need to focus on designing and developing websites in a way through which the conversion rate increases, and individuals involved in higher purchases overall.

\section{Conclusion}

E-commerce has changed the way businesses used to operate and function. Organisations have been able to attain various opportunities and benefits on which they have optimized to attain a good position and image in the marketplace. With regards to business performance, it has been identified that firms are able to significantly augment their performance level due to increased marketplace, better growth opportunities, lesser operating costs, a fewer requirement of investments, lesser risks, and more. While ample companies have taken use of this business model and achieved a high growth rate, others have not been able to rightly optimize on the opportunities. Along with several advantages, firms also face certain limitations and challenges related to implementing Ecommerce. It has therefore been concluded that even though various potential benefits are present related to
E-commerce, organizations have to develop a critical strategic approach to attain those advantages in an adequate manner. Through effective leadership and the right planning, companies may utilize the opportunities and develop a significant position in the industry.

\section{Acknowledgements}

This work is supported by the:

1. NIP-2021-03 / 12.04.2021 " Extraction and analysis of parametric data from the Internet of Things "

2.NIP-2021-09 / 12.04.2021 "Analysis and optimization by algorithms for the classification of signals from Smart IoT devices"

3.National Science Program "Information and Communication Technologies for Unified Digital Market in Science, Education and Security".

\section{References}

[1]. Gregory, G. D., Ngo, L. V., \& Karavdic, M. (2019). Developing e-commerce marketing capabilities and efficiencies for enhanced performance in business-tobusiness export ventures. Industrial Marketing Management, 78, 146-157.

[2]. Soni, V. D. (2020). Emerging Roles of Artificial Intelligence in ecommerce. International Journal of trend in scientific research and development, 4(5), 223-225.

[3]. Tzavlopoulos, I., Gotzamani, K., Andronikidis, A., \& Vassiliadis, C. (2019). Determining the impact of ecommerce quality on customers' perceived risk, satisfaction, value and loyalty. International Journal of Quality and Service Sciences, 11(4), 576-587.

[4]. Nyagwencha, A. N. (2018). E-Commerce Adoption And Business Performance Of Automotive Firms In Nairobi, Kenya (Doctoral dissertation, University of Nairobi).

[5]. Shaytura, S. V., Kozhayev, Y. P., Ordov, K. V., Antonenkova, A. V., \& Zhenova, N. A. (2017). Performance evaluation of the electronic commerce systems. Espacios, 38(62), 11-11.

[6]. Iliev, I., \& Dimitrov, G. P. (2014, May). Front end optimization methods and their effect. In 2014 37th International Convention on Information and Communication Technology, Electronics and Microelectronics (MIPRO) (pp. 467-473). IEEE. doi 10.1109/MIPRO.2014.6859613

[7]. Dimitrov, G. P., Panayotova, G., \& Kostadinova, I. (2017, September). Approaches for optimization of web pages loading via analysis of the speed of requests to the database. In 4th International Conference on Artificial Intelligence and Pattern Recognition (pp. 58-63).

[8]. Aktymbayeva, A. S., Koshkimbayeva, U. T., Zhakupova, A. A., Alimgaziyeva, N. K., \& Amir, B. M. (2018). E-commerce evaluation and e business trends. International Journal of Innovative Technologies in Economy, 1(13). 
[9]. Sharma, S., Mahajan, S., \& Rana, V. (2019). A semantic framework for ecommerce search engine optimization. International Journal of Information Technology, 11(1), 31-36.

[10]. Sabou, S., Avram-Pop, B., \& Zima, L. A. (2017). The impact of the problems faced by online customers on ecommerce. Studia Universitatis BabesBolyai, 62(2), 77.

[11]. Orendorff, A. (2019). Global ecommerce statistics and trends to launch your business beyond borders. Global Ecommerce.
[12]. Schmitz, A. J. (2016). Building Trust in E-commerce Through Online Dispute Resolution. Research Handbook on Electronic Commerce Law, Edward Elgar, 15-15.

[13]. Jung, S. M., \& Park, S. L. (2016). A Study on the Effect of the Facilitating Factors of B2C eCommerce on the Online Shopping and the Overseas Direct Purchase. International commerce and information review, 18(2), 27-51.

[14]. Pradhan, N., Deolalikar, V., \& Li, K. (2015, October). Atypical queries in ecommerce. In Proceedings of the 24th ACM International on Conference on Information and Knowledge Management (pp. 1767-1770). 